\title{
COVID-19 Pandemic and Telephone Triage before Attending Medical Office: Problem or Opportunity?
}

\author{
Gabriele Cervino*(1) and Giacomo Oteri \\ Department of Biomedical and Dental Sciences and Morphological and Functional Imaging, Messina University, \\ 1-98100 Messina, Italy; oterig@unime.it \\ * Correspondence: gcervino@unime.it; Tel.: +39-090-2216920
}

Received: 14 May 2020; Accepted: 18 May 2020; Published: 20 May 2020

check for updates

\begin{abstract}
During the COVID-19 emergency, the medical operating protocols have been largely modified for reducing any type of contamination risk, for working in a safe way and for making the patient feel in a safe environment. Telemedicine, smart phones and apps could represent important devices for the community, in order to prevent virus trasmission and to perform quick diagnosis and management at medical offices. This manuscript could be useful for clinicians with regard to the current state of the effectiveness of the telephone triage in this COVID-19 epidemic period. Therefore, it could be an important starting point for future perspectives about telemedicine and virtual patient management.
\end{abstract}

Keywords: COVID-19; virus; epidemiology; infection risk; telemedicine

In response to the COVID-19 pandemic, new prevention measures have been announced by governments around the world, measures that severely limit social interactions and travel, as well as visits at medical and dental offices.

According to guidelines, many clinicians and practitioners have changed their way of working, shifting to remote or smart working. While doctors, orthopedic surgeons, dentists and plastic surgeons have continued to provide non-deferred, urgent and emergency care, the restrictions pose a unique challenge for preventing contamination during the conventional front of house visits of many patients.

For this reason, the professional medical associations have worked to provide effective guidance on conducting telephone consultations, before visiting the patients. However, although this could be useful for controlling patient health status, medical and dental services cannot be based exclusively on remote assistance, because they are medical disciplines founded on experience and patient contact [1-9].

The professional and ethical conduct of the clinicians who carry out medical and dental care during this COVID-19 pandemic is a focus of attention in this period of global emergency. This pandemic is deeply changing the clinician's medical habits, work attitudes and patient management [10-14].

COVID-19 is a respiratory virus that spreads mainly through contact with the respiratory droplets of infected people, direct mucous contact with saliva droplets or by mucous contact with those droplets on hands, on objects or on infected surfaces [1,4,13-18].

The dentist, working close to the patient and being in contact with saliva, is among the most exposed to the virus. However, daily dental practice has always been performed with personal protective equipment and with high attention to the hygiene standards of disinfection and sterilization [19-21].

Nevertheless, at this moment, the classification of the patients should be mandatory and should be carried out through preventive triage: a first evaluation summary of epidemiological data, including information about travel history, is mandatory. Then, the clinical presentation results reported by the patient himself are fundamental to assessing the probability of a coronavirus infection [22-25]. 
Triage prevention method gives clinicians the possibility of recognizing patients as potentially infected by coronavirus before accessing treatment [20,22-26].

The use of triage has been reported in the literature as effective in other areas, especially in the emergency medicine field and, therefore, reporting with the use of a questionnaire for the evaluation of symptoms in the context of primary care could be effective during the COVID-19 pandemic $[14,18,20-26]$.

Triage consists of two phases: telephone and 'in-office'. Telephone triage makes it possible to evaluate the patient's general health, identify the possible presence of symptoms related to COVID-19, as well as risky behaviors that may have increased the chances of the patient's contact with infected subjects. There are two main reasons for concern regarding a second triage in office. Firstly, the predicted incubation period of COVID-19 makes it possible that the patient may have developed symptoms just before the clinical visit and after the phone call. Then, at the office, a second check records the patients as safe for being involved in the consequent medical treatments. It is also necessary to gather this data to protect clinicians and practitioners by a legal point of view too. The triages that took place in the studio must be signed and dated (with telephone triage data and in office triage data), and an appropriate questionnaire should be used. Triage is essential, because it represents an operative filter. Moreover, the patients' cooperation in this situation is essential, as community health is important. The goal of patient examination is clinical decision, diagnosis and treatment; at this moment, the screening of COVID-19 risk patients and the accidental detection of asymptomatic pathologies still represent a challenge for clinicians [12-28].

At present, the consideration of a complete telemedicine system may seem premature, particularly in light of the general expectation that stricter social distancing measures will soon be relaxed. The deadlines are, however, indefinite, and the resumption of 'normal' practice could still be hampered by the potential secondary peak in COVID-19 cases.

Currently, numerous smartphone applications, such as DOCTOROral@ [28] diagnosis, are available for medical practitioners, clinicians and dentists, in order to perform presumptive quick diagnosis just by viewing a picture taken on the patient's smartphone.

Remote consultations are essential for reducing the risk of infections. The operators should be invited to change their work habits to control the risk of contamination, and are asked to exercise their professional judgment to decide the level of post-therapy assistance and how to provide it.

Author Contributions: Writing—review and editing, G.C.; supervision, G.O.; All authors have read and agreed to the published version of the manuscript.

Funding: This research received no external funding.

Conflicts of Interest: The authors declare no conflict of interest.

\section{References}

1. Zhang, W.; Wang, Y.; Yang, L.; Wang, C. Suspending Classes Without Stopping Learning: China's Education Emergency Management Policy in the COVID-19 Outbreak. J. Risk Financial Manag. 2020, 13, 55. [CrossRef]

2. Yu, H.; Sun, X.; Solvang, W.D.; Zhao, X. Reverse Logistics Network Design for Effective Management of Medical Waste in Epidemic Outbreaks: Insights from the Coronavirus Disease 2019 (COVID-19) Outbreak in Wuhan (China). Int. J. Environ. Res. Public Health 2020, 17, 1770. [CrossRef] [PubMed]

3. Yang, Y.; Shang, W.; Rao, X. Facing the COVID-19 outbreak: What should we know and what could we do? J. Med. Virol. 2020, 10, 536-537. [CrossRef] [PubMed]

4. Fiorillo, L.; Cervino, G.; Matarese, M.; D'Amico, C.; Surace, G.; Paduano, V.; Fiorillo, M.T.; Moschella, A.; La Bruna, A.; Romano, G.L.; et al. COVID-19 Surface Persistence: A Recent Data Summary and Its Importance for Medical and Dental Settings. Int. J. Environ. Res. Public Health 2020, 17, 3132. [CrossRef] [PubMed]

5. Xu, B.; Kraemer, M.U.G. Open access epidemiological data from the COVID-19 outbreak. Lancet Infect. Dis. 2020. [CrossRef] 
6. Wu, Z.; McGoogan, J.M. Characteristics of and Important Lessons from the Coronavirus Disease 2019 (COVID-19) Outbreak in China: Summary of a Report of 72314 Cases from the Chinese Center for Disease Control and Prevention. Jama 2020, 323, 1239-1242. [CrossRef]

7. Wang, C.; Pan, R.; Wan, X.; Tan, Y.; Xu, L.; Ho, C.S.; Ho, R.C. Immediate Psychological Responses and Associated Factors During the Initial Stage of the 2019 Coronavirus Disease (COVID-19) Epidemic among the General Population in China. Int. J. Environ. Res. Public Health 2020, 17, 1729. [CrossRef]

8. Wang, C.; Cheng, Z.; Yue, X.-G.; McAleer, M. Risk Management of COVID-19 by Universities in China. J. Risk Financial Manag. 2020, 13, 36. [CrossRef]

9. De Stefano, R. Psychological Factors in Dental Patient Care: Odontophobia. Medicina 2019, 55, 678. [CrossRef]

10. Fiorillo, L. Oral Health: The First Step to Well-Being. Medicina 2019, 55, 676. [CrossRef]

11. The Lancet. COVID-19: Fighting panic with information. Lancet 2020, 395, 537. [CrossRef]

12. Tetro, J.A. Is COVID-19 Receiving ADE from Other Coronaviruses? Microbes Infect. 2020, 22, 72-73. [CrossRef] [PubMed]

13. Nishiura, H. Backcalculating the Incidence of Infection with COVID-19 on the Diamond Princess. J. Clin. Med. 2020, 9, 657. [CrossRef] [PubMed]

14. Liu, Z.; Magal, P.; Seydi, O.; Webb, G. Understanding Unreported Cases in the COVID-19 Epidemic Outbreak in Wuhan, China, and the Importance of Major Public Health Interventions. Biology 2020, 9, 50. [CrossRef] [PubMed]

15. Roosa, K.; Lee, Y.; Luo, R.; Kirpich, A.; Rothenberg, R.; Hyman, J.M.; Yan, P.; Chowell, G. Short-term Forecasts of the COVID-19 Epidemic in Guangdong and Zhejiang, China: February 13-23, 2020. J. Clin. Med. 2020, 9 , 596. [CrossRef]

16. Repici, A.; Maselli, R.; Colombo, M.; Gabbiadini, R.; Spadaccini, M.; Anderloni, A.; Carrara, S.; Fugazza, A.; Di Leo, M.; Galtieri, P.A.; et al. Coronavirus (COVID-19) outbreak: What the Department of Endoscopy Should kKnow. Gastrointest. Endosc. 2020. [CrossRef]

17. Porcheddu, R.; Serra, C.; Kelvin, D.; Kelvin, N.; Rubino, S. Similarity in Case Fatality Rates (CFR) of COVID-19/SARS-COV-2 in Italy and China. J. Infect. Dev. Ctries. 2020, 14, 125-128. [CrossRef]

18. Peeri, N.C.; Shrestha, N.; Rahman, M.S.; Zaki, R.; Tan, Z.; Bibi, S.; Baghbanzadeh, M.; Aghamohammadi, N.; Zhang, W.; Haque, U. The SARS, MERS and novel coronavirus (COVID-19) epidemics, the newest and biggest global health threats: What lessons have we learned? Int. J. Epidemiol. 2020. [CrossRef]

19. van Doremalen, N.; Bushmaker, T.; Morris, D.H.; Holbrook, M.G.; Gamble, A.; Williamson, B.N.; Tamin, A.; Harcourt, J.L.; Thornburg, N.J.; Gerber, S.I.; et al. Aerosol and Surface Stability of SARS-CoV-2 as Compared with SARS-CoV-1. N. Engl. J. Med. 2020, 382, 1564-1567. [CrossRef]

20. Kampf, G.; Todt, D.; Pfaender, S.; Steinmann, E. Persistence of coronaviruses on inanimate surfaces and their inactivation with biocidal agents. J. Hosp. Infect. 2020, 104, 246-251. [CrossRef]

21. Warnes, S.L.; Little, Z.R.; Keevil, C.W. Human Coronavirus 229E Remains Infectious on Common Touch Surface Materials. mBio 2015, 6, e01697. [CrossRef]

22. Yang, Z.R.; Sun, F.; Zhan, S.Y. [Risk of bias assessment: (1) overview]. Zhonghua Liu Xing Bing Xue Za Zhi 2017, 38, 983-987. [CrossRef] [PubMed]

23. Cicciù, M. Water Contamination Risks at the Dental Clinic. Biology 2020, 9, 43. [CrossRef] [PubMed]

24. Smieszek, T.; Lazzari, G.; Salathe, M. Assessing the Dynamics and Control of Droplet- and Aerosol-Transmitted Influenza Using an Indoor Positioning System. Sci. Rep. 2019, 9, 2185. [CrossRef] [PubMed]

25. Spagnuolo, G.; De Vito, D.; Rengo, S.; Tatullo, M. COVID-19 Outbreak: An Overview on Dentistry. Int. J. Environ. Res. Public Health 2020, 17, 2094. [CrossRef]

26. Cavallo, L.; Marcianò, A.; Cicciù, M.; Oteri, G. 3D Printing beyond Dentistry during COVID 19 Epidemic: A Technical Note for Producing Connectors to Breathing Devices. Prosthesis 2020, 2, 46-52. [CrossRef]

27. Fiorillo, L. Chlorhexidine Gel Use in the Oral District: A Systematic Review. Gels 2019, 5, 31. [CrossRef]

28. Campisi, G.; Panzarella, V.; Di Fede, O.; Mauceri, R.; Capocasale, G. Doctoral: The Free App For Tutoring In Supportive Oral Care. Support. Care Cancer 2018, 26, S114.

(C) 2020 by the authors. Licensee MDPI, Basel, Switzerland. This article is an open access article distributed under the terms and conditions of the Creative Commons Attribution (CC BY) license (http://creativecommons.org/licenses/by/4.0/). 